\title{
ORIGEN Y EVOLUCIÓN DE LA COMUNIDAD PALESTINA EN CHILE
}

\section{THE ORIGIN AND EVOLUTION OF PALESTINIAN COMMUNITY IN CHILE}

\author{
Julieta Espín Ocampo ${ }^{1}$ \\ ORCID: 0000-0002-7799-6438
}

\section{RESUMEN}

El artículo analiza las características de la comunidad palestina en Chile, recurriendo tanto al origen y evolución histórica como al proceso de construcción identitaria, especialmente a través de las instituciones que han creado en ese país. Aunque dicha comunidad ya se encuentra integrada a la sociedad chilena con pérdida de elementos identitarios como la lengua árabe, mantiene un sentimiento de pertenencia y cohesión respecto a sus miembros, además de interés y compromiso político en relación con la tierra de sus ancestros.

Palabras clave: Chile; Palestina; comunidad; migraciones; refugiados; identidad nacional.

\begin{abstract}
The article analyzes the characteristics of the Palestinian community in Chile, resorting to both the origin and historical evolution and the process of identity construction, especially through the institutions that they have created in that country. Although this community is already integrated into Chilean society with the loss of identity elements such as the Arabic language, it maintains a sense of belonging and cohesion within its members, in addition to interest and political commitment regarding the land of their ancestors.
\end{abstract}

Keywords: Chile; Palestine; migration; refugees; community; national identity.

1 Universidad Europea, Departamento de Ciencias Jurídicas y Políticas, Madrid, España. Doctora en Estudios Internacionales Mediterráneos por la Universidad Autónoma de Madrid. Correo electrónico: julietaespinocampo@gmail.com 


\section{Introducción}

Los inicios de la migración palestina a América Latina se remontan a mediados del siglo XIX, y hoy Chile y Honduras acogen a las comunidades más grandes en la región: aproximadamente entre 300000 y 500000 personas en Chile y 280000 en Honduras (Arad, 2018; Moore y Mathewson, 2013). Así pues, Chile alberga a la comunidad palestina más numerosa y organizada fuera de Oriente Medio: aproximadamente el $1,8 \%$ de la población chilena tiene orígenes palestinos. Producto de varias décadas de inmigración, este colectivo que está distribuido por todo el territorio chileno, es social y económicamente heterogéneo, aunque con atributos culturales y sociales que denotan cierta voluntad de mantener rasgos identitarios y lazos con Palestina.

El objetivo del presente trabajo es exponer la evolución de la comunidad palestina en Chile, con el propósito de permitir analizar sus actuales características identitarias y su grado de integración en la sociedad chilena. Para ello, el artículo inicia con una revisión histórica de los factores de expulsión y atracción de este fenómeno migratorio. Muestra también las características de los diferentes movimientos migratorios de grupos palestinos que llegaron al país sudamericano, así como su proceso de adaptación e integración en la sociedad chilena. Asimismo, describe el proceso de construcción identitaria de este grupo que corre paralelo a su integración al país de acogida. Finalmente, evalúa la actual situación de esta comunidad y los lazos de identidad que existen entre esta y Palestina como origen común.

Para la elaboración de este trabajo se realizó una revisión del estado de la cuestión en fuentes académicas, prestando atención a la evolución histórica de la comunidad palestina en Chile y al proceso de construcción identitaria que paulatinamente fue surgiendo en su seno. Posteriormente, desde una vertiente cualitativa, se revisaron fuentes de diversas instituciones palestinas de carácter cultural, social y deportivo en el país andino, que permitieran evaluar el nivel de cohesión en la comunidad, así como su labor en la promoción de la propia identidad y su relación con Palestina. Dicha información fue complementada con material bibliográfico no especializado.

\section{Génesis y desarrollo de la migración palestina a Chile}

Las primeras migraciones de palestinos al continente americano se enmarcan en un proceso mucho más amplio de movimientos migratorios entre $1860 \mathrm{y}$ 
1914, cuando aproximadamente 60 millones de europeos y unos 1,2 millones de súbditos otomanos (turcos, armenios, árabes, judíos o griegos) emigraron al continente americano (Baeza, 2013). Aunque las autoridades de los diferentes países de acogida primaban y preferían la inmigración europea, para los grupos árabes, América se convirtió en un vastísimo continente de oportunidades; y rutas y destinos se fueron construyendo desde el territorio canadiense hasta Tierra de Fuego. Entre los principales factores de atracción se encontraban salarios relativamente más altos, debido a la creciente demanda de empleo en todo el continente por los procesos de industrialización en Norteamérica y de creciente producción agrícola en Sudamérica (Araneda, 2015), así como la necesidad de poblar y hacer producir enormes extensiones de terreno.

Según Zahded (2012), entre 1860 y1925 casi un millón y medio de árabes emigraron a América Latina, y entre estos grupos, unos 40000 palestinos. Existen evidencias de la participación de mercaderes palestinos en diferentes ferias en territorio estadounidense desde la segunda parte del siglo XIX, y algunos de ellos abrirían nuevas rutas hacia el sur, alcanzando México, Honduras o El Salvador (Baeza, 2013), a la vez que otros abrían rutas directas con Argentina y otras partes de Sudamérica. No obstante, las ciudades de destino donde había comunidades sirias y libanesas más grandes, que supusieran una competencia para el comercio, resultaron menos atractivas (Sabella, 2017), por lo que los palestinos cruzaron el continente para asentarse más cerca de las costas del Pacífico, en Perú, Bolivia o Ecuador, pero especialmente en Chile.

En este primer periodo y hasta la desaparición del Imperio Otomano, los palestinos y árabes, en general, que arribaron a países latinoamericanos fueron identificados por los gobiernos y sociedades que les recibieron como "turcos", debido a sus pasaportes otomanos, independientemente de la comunidad a la que pertenecieran. Esta etiqueta perduraría décadas después de la desaparición del imperio (Zahded, 2012). Esta particularidad de las primeras oleadas de inmigrantes árabes en América, en general, y en Chile, en particular, impedirán un censo claro de este colectivo. De hecho, no será hasta después de 1924 cuando se comenzó a distinguir a los grupos inmigrantes como sirios, libaneses, palestinos o transjordanos (Araneda, 2015), debido a la partición del Levante por parte de franceses e ingleses a través del sistema de mandatos, que comenzaron a emitir documentos de viaje con dichas denominaciones nacionales.

Araneda (2015) realiza un amplio análisis sobre las dificultades de contabilizar cualitativamente a inmigrantes durante esa época. Plantea que esta dificultad se debe, además de las cuestiones relativas al origen de los documentos de identificación-cuando se contaba con ellos-, a cuestiones de desconocimiento del "otro", que el autor considera justificado por una visión orientalista, en los 
términos descritos por Edward Said, que en Latinoamérica se importó de Francia o Reino Unido. El orientalismo, que ponía a la civilización occidental por encima de cualquier otro pueblo o cultura, era una herramienta ideológica que justificaba los procesos colonizadores de las potencias europeas en el resto del mundo. Así pues, a muchos inmigrantes árabes se les catalogó en los censos locales como "mahometanos", basándose en los rasgos étnicos y la lengua, aunque esos primeros inmigrantes eran mayoritariamente cristianos.

Los primeros grupos palestinos emigraron a Chile a finales del siglo XIX, motivados principalmente por razones económicas, desde establecer negocios hasta salir de la pobreza. Por ese entonces, gobiernos como el argentino o chileno promovían la inmigración como estrategia para poblar y desarrollar sus vastísimos territorios, aunque primaban sobre todo la inmigración europea. Los árabes, pues, no recibieron ningún trato preferencial, no se les concedió tierras o lugares para vivir (Sumamé, 2003) y sus esfuerzos por salir adelante les acarrearon fama de austeros y trabajadores (Sabella, 2017).

A principios de siglo, nuevos inmigrantes llegaron huyendo de la conscripción forzosa impuesta por el Imperio Otomano en 1909, durante su proceso de modernización. En ese entonces, los llamados Jóvenes Otomanos impusieron el servicio militar obligatorio a los súbditos de las minorías religiosas, hasta entonces exentos (Douglas, 2010). El posterior desmembramiento del Imperio Otomano, el mandato británico en Palestina y las crecientes tensiones entre la población árabe y los inmigrantes judíos, promovieron un incremento de la migración hacia Chile, que vería sus máximos históricos entre las décadas de 1910 y 1930 (Sabella, 2017; Araneda, 2015), aunque durante el periodo de la Primera Guerra Mundial hubo una disminución debido a las limitaciones impuestas a las conexiones intercontinentales entre Asia, Europa y América (Araneda, 2015). A estos factores de expulsión se sumaría el efecto llamado como un nuevo elemento de atracción: poco a poco, se establecieron redes familiares e incluso vecinales que atrajeron nuevos inmigrantes. De 1895 a 1940, entre 8 000 y 10000 árabes llegaron a Chile. De ellos, $51 \%$ procedía de Palestina, 30 $\%$ de Siria y 19 \% de El Líbano (Agar, 1997).

Los inmigrantes de las primeras oleadas se dedicaron a la pesca, a la industria del cobre, a la ganadería (Bascuñan-Wiley, 2017), pero principalmente al comercio. Algunos establecieron pequeños locales comerciales y otros se dedicaron al comercio ambulante o de puerta en puerta. Sus mercancías iban desde artículos religiosos, algunos relacionados con sus lugares de procedencia en Tierra Santa (Baeza, 2013), hasta ropa, jabón, botones, peines, espejos, o carretes de hilo (Sabella, 2017) o tallado en nácar (Sumamé, 2003). Muchos se asentaron en poblaciones grandes como Santiago (en 1952, el $39 \%$ de los 
palestinos vivían en la capital) o Valparaíso, aunque otros prefirieron ciudades secundarias en otras zonas del país y se dedicaron, además del comercio, en menor medida, a labores agrícolas. Sin oficio especializado ni redes sociales, sin capital para grandes inversiones o para contratar empleados, aunado a la barrera del idioma, el comercio ambulante fue la actividad económica ideal para los primeros migrantes.

El baisano o turco "falte" recorría grandes distancias para ofrecer sus productos, incluso ahí donde no llegaban sus competidores chilenos (Agar, 1997). Su dispersión geográfica y su actividad comercial, casi exclusiva, en comunidades remotas del país, dejaron su impronta en la cultura popular chilena. Un viejo dicho indica que: En cada pueblo hay tres cosas: un cura, un policía y un palestino. Aquellos que podían instalar un pequeño bazar o taller artesanal (preferentemente textil), solían vivir en la misma tienda, que era casa-habitación, lo que les permitía ahorrar y, paulatinamente, enviar pequeñas remesas a Palestina $\mathrm{y}$, poco a poco, traer e instalar a los familiares (hermanos, esposa, primos, etc.), empleándolos también en el negocio familiar, en un proceso de décadas conocido como “inmigración en cadena” (Agar, 1997; Baeza, 2013; Sumamé, 2003).

Esas primeras oleadas comprendían, sobre todo en el caso palestino, cristianos ortodoxos, que establecieron sus centros deportivos y contribuyeron a la economía chilena mediante su actividad comercial y productiva (textil, sobre todo) en periodos de expansión económica, donde se promovía la inmigración al extenso territorio chileno. Se integraron en la sociedad que los acogía a través de actividades sociales. Los palestinos provenían en su mayoría de ciudades cercanas a Jerusalén, como Beit Yala, Belén, y Beit Sahur (Molina, 2014), pero también de la propia Ciudad Santa o Ramallah y tal como se replica en otros países, las redes familiares y comunitarias promovieron nuevas migraciones de palestinos a Chile, impulsadas también por el deterioro gradual de la situación en la Palestina histórica. De hecho, la estructura familiar de tipo patriarcal permitiría la preservación de costumbres y tradiciones en las siguientes generaciones $(\mathrm{Su}-$ mamé, 2003).

En 1941, Ahmad Hassan Mattar publicó la Guía social de la colonia árabe en Chile, una investigación financiada por el Club Palestino-del que se hablará más adelante-, que pretendía ser un censo de las comunidades siria, libanesa y palestina en el país. Respecto a esta última, se señala que la comunidad, la más grande de las tres, estaba conformada por 1232 familias que sumaban 6 590 individuos: 430 familias de Beit Yala; 417 familias de Belén; 60 familias originarias de Jerusalén y Ein Karim; 68 familias de Beit Sahur; 5 familias de Taybeh, en la zona de Ramallah; 4 familias de la propia Ramallah, 8 familias provenientes de Jifna, y otras 240 familias provenientes de otras partes 
de Palestina (Mattar, citado por Sabella, 2017). Como se observa, la inmensa mayoría provenía de Belén y Beit Yala, poblaciones predominantemente cristianas. De hecho, se calcula que hoy los chileno-palestinos triplican el número de cristianos que aún quedan en Palestina (Holston, 2005).

La especificidad de su pertenencia a la religión cristiano-ortodoxa en un país de mayoría católica no sólo no fue un impedimento para su integración, sino que permitió cierta diferenciación que prolongó la especificación de la comunidad por varias décadas. Así, en 1917, se estableció la iglesia ortodoxa de San Jorge en la comuna de Recoleta, entonces un sector periférico de clase baja de la capital chilena, enclavada en lo que hoy se conoce como el barrio Patronato (en el municipio de Recoleta), donde se asentaron, junto a la comunidad palestina, la siria y libanesa, convirtiéndolo en un barrio comercial con fuertes influencias árabes y en el que hoy perviven numerosos negocios que así lo evidencian, como bazares y restaurantes árabes, así como carteles en el mismo idioma. Apenas unos años después, en 1920 se fundaría el Club Palestino, un centro comunitario que desde entonces organiza eventos sociales, culturales y deportivos, así como el famoso Club Deportivo Palestino de fútbol, que hoy juega en la primera división de ese país con los colores nacionales palestinos y en cuyo estadio Municipal, La Cisterna de Santiago, hondea la bandera palestina.

Aunque mucho menos significativa, también en las primeras oleadas se registraron inmigrantes musulmanes palestinos. Estos tendieron a agruparse con los musulmanes sirios, mucho más numerosos, con el común interés de proteger su herencia cultural e identidad islámica, muy ligada a la preocupación de mantener la lengua árabe entre sus descendientes. En 1926 se funda la Sociedad Unión Musulmana, y en 1927 la Sociedad de Socorros Mutuos y de Beneficencia Islámica, que, al igual que las instituciones creadas por los palestinos cristianos, apoyarían desde Chile las luchas nacionales de independencia contra las potencias mandatarias y contra las pretensiones sionistas en Palestina (Araneda, 2015). Será también iniciativa de la comunidad musulmana el primer colegio árabe en suelo chileno, establecido en 1933. Este colegio bilingüe árabeespañol pretendía afrontar la pérdida de la lengua materna, a los que se sumaron el Colegio Árabe de Valparaíso y Viña del Mar, fundado en 1972 y el Colegio Árabe de Santiago, creado en 1980.

No obstante, el éxito fue limitado debido a la integración de esta colectividad en la sociedad chilena, dado que el intercambio económico y social con la sociedad de acogida fue siempre en español (Araneda, 2015) y, como se ha mencionado anteriormente, el rechazo y las burlas de los chilenos por el castellano hablado por los árabes recién llegados (Zahded, 2012) les impulsó a favorecer el uso del idioma local en casa. Sin embargo, la religión no fue, ni en el caso de los 
musulmanes ni en el de las minorías cristianas, el elemento cohesionador principal de las comunidades de inmigrantes. Los musulmanes apenas han tenido visibilidad en Chile y el resto del continente americano y, tanto para maronitas como ortodoxos, la religión no se convirtió en el elemento central de sus comunidades, sino que primaban más las referencias étnica y lingüística como elementos de cohesión (Moore y Mathewson, 2013); es decir, el reconocerse como árabes y el compartir una lengua, aunque con el tiempo, esta segunda seña de identidad prácticamente terminaría por perderse.

Una tercera oleada se produjo tras de la Segunda Guerra Mundial, con la reconfiguración de Oriente Medio. Básicamente, la inmigración de origen sirio y libanés disminuiría notablemente gracias a los procesos de independencia nacionales que mejorarían las condiciones de la población. Sin embargo, las crecientes tensiones entre los árabes y los inmigrantes judíos a Tierra Santa y la posterior partición y guerra influirían en el éxodo de palestinos a Chile, aunque el número comenzó a declinar $\mathrm{y}$, prácticamente, desaparece como fenómeno social (Agar y Saffín, 2005). En las últimas décadas, serían Brasil y Venezuela los principales países receptores de palestinos, todos del periodo post-Nakba, tras la creación del Estado de Israel en 1948, y mayoritariamente musulmanes (Baeza, 2013).

No será hasta la primavera de 2008, cuando se observa un nuevo flujo migratorio, la llegada de 117 refugiados palestinos provenientes de Irak, donde vivían acogidos desde 1948, en esta ocasión, huyendo de la guerra en ese país, en total, 58 adultos y 59 menores agrupados en 29 familias (Contreras, 2015). Se calcula que, hasta antes de la última guerra, en Irak existía una comunidad de unos 34 000 refugiados palestinos (Smith, 2010). La invasión estadounidense los obligó nuevamente a desplazarse $y$, junto con los iraquíes, huyeron de la barbarie buscando protección en el campamento de al-Tanf, en la frontera sirio-iraquí, de donde partieron hacia Chile, acogidos a través de un programa de reasentamiento lanzado a nivel global por el Alto Comisionado de las Naciones Unidas para los Refugiados (ACNUR).

Chile y Brasil fueron los países de Latinoamérica que respondieron con más generosidad a la llamada de ACNUR para acoger a los refugiados palestinos que volvían a desplazarse para salvar la vida. De acuerdo con el estudio de Paula Lekanda (2008), hay varias razones que explican la postura chilena. La entrada de estos refugiados significaría beneficios económicos para el país, si se atiene el antecedente de las primeras oleadas de migrantes palestinos, sobre todo en la actividad comercial. Asimismo, su presencia reforzaría la multiculturalidad nacional, donde ya existe, por ejemplo, una creciente demanda e interés por la comida y la música árabe, y porque al ser musulmanes, su presencia 
sería una oportunidad para aumentar la tolerancia religiosa en la población en general. Además, Lekanda argumenta el principio de afinidad, por el cual los países deben otorgar ayuda a personas semejantes a nosotros que sean reconocidos como "familiares étnicos o nacionales" (2008, p. 51).

Dado el tamaño de la colonia palestina en el país, se impone la obligación de recibir a estos "parientes", ligado a un principio de retribución, dado que la nación chilena reconoce las contribuciones de la colonia palestina al desarrollo económico del país. En este proceso, no se puede obviar el papel del lobby palestino, es decir, el activismo de la comunidad palestina del país, ni tampoco la propia experiencia del devenir histórico de Chile. Durante la dictadura de Augusto Pinochet en los años setenta, miles de chilenos debieron partir al exilio, incluida Michel Bachelet, presidenta del país en 2008, cuando fue acogido este grupo.

Estos refugiados comparten Haifa como lugar de origen, pero socialmente constituían una unidad bastante heterogénea con una diversidad de perfiles profesionales, desde profesores universitarios hasta individuos con un nivel de escolaridad baja. El programa de reubicación implementado por ACNUR y el gobierno chileno, con el apoyo de organizaciones civiles y religiosas como la Vicaría de la Solidaridad, consistía en un apoyo monetario mensual para cubrir las necesidades básicas de cada familia, vivienda y otros programas para ayudarles a su establecimiento en el país (Smith, 2010), pero las diferencias sociales serían decisivas para facilitar su adaptación a la sociedad chilena: la educación y el conocimiento o desconocimiento del idioma serían cruciales.

Las subvenciones a estas familias se eliminaron al año y medio de su llegada a Chile, lo que dificultó aún más la integración de las más pobres a las comunidades donde habían sido destinadas. Al respecto, un estudio demuestra el trato discriminatorio y abusivo que algunos niños palestinos llegaron a sufrir por sus pares en los colegios donde fueron matriculados, principalmente en barrios de clase media baja, así como las dificultades económicas y cierto rechazo social padecido por sus familias (Carrasco, Molina y Baltar, 2013).

\section{Evolución socioeconómica y política}

Así pues, los palestinos se integraron paulatinamente a la sociedad de acogida, participando en la vida económica, social y política de Chile. Las primeras generaciones incidieron en el desarrollo económico del país con el comercio y el desarrollo industrial, sobre todo en el sector textil, a la vez que se adaptaban a su nueva patria. Las segunda y terceras generaciones ahondarán su integración, 
contribuyendo en todas las áreas de la sociedad chilena: la política, las ciencias, los negocios, las profesiones, el arte, las comunicaciones, entre muchas otras.

Después del crack económico de 1929 y con el inicio de la Gran Depresión, los países latinoamericanos debieron ajustarse a la nueva realidad económica mundial, que recortó abruptamente la demanda de materias primas provenientes de la región. La estrategia emprendida por algunos gobiernos fue implantar políticas desarrollistas basadas en el modelo de sustitución de importaciones, que requería un empresariado nacional dispuesto a invertir en el sector secundario o manufacturero. Los palestinos encontraron en estas políticas un nicho de crecimiento económico tanto en la industria, principalmente textil, como en el sector bancario, necesario para financiar la industrialización del país. Un ejemplo claro fue la fundación del BCI o Banco de Crédito e Inversiones en 1937 por Juan Yarur, también dueño de fábricas textiles o Parque Arauco, de la familia Said, que cuenta con centros comerciales también en Perú y Colombia (Baeza, 2013; Molina, 2014).

Cabe destacar que el ascenso económico y social de los palestinos no fue ni de lejos homogéneo. Por un lado, los grandes empresarios que comenzaron a insertarse en la alta sociedad chilena, aunque no exentos de discriminación al considerárseles "nuevos ricos turcos" (Sumamé, 2003, p. 53). Por otro lado, los pequeños comerciantes y manufactureros que se unieron a las clases medias nacionales y que enviaron a sus hijos a las universidades a estudiar profesiones tradicionales como medicina, derecho, ingenierías varias, etc. (Baeza, 2013). No obstante, en ambos casos la mejora de su situación económica facilitó la aceptación social y el acceso a nuevas áreas (Agar 1997) como la cultura, la académica o la política, aunque ésta costaría un poco más. Si bien en la década de 1940 ya hay un congresista de origen árabe, en la década siguiente, el gobierno del presidente Ibañez contó con dos ministros de ascendencia palestina (Baeza, 2013).

A principios de los setenta, la polarización política que vivía América Latina, en general, y Chile, en particular, permeó también en la comunidad palestina, dividiéndola entre una nueva generación de políticos izquierdistas y un sector más conservador relacionado con las grandes familias capitalistas (Baeza, 2013). Esta división se hizo evidente durante el gobierno de Salvador Allende y el posterior golpe de estado y dictadura de Augusto Pinochet. En el gobierno de Salvador Allende, la industria textil, buena parte en manos palestinas, era de las que más mano de obra utilizaba y cuyos trabajadores estaban más politizados. Allende nacionalizó las fábricas de varias familias palestinas (Yarur, Sumar, Said e Hirmas) por presión de los sindicatos, éstas fueron devueltas rápidamente a sus dueños tras el golpe militar. Las familias Yarur, Sumar e Hirmas 
siguen hoy teniendo en sus manos la industria textil del país (Zahded, 2012) y la valoración de buena parte del empresariado chileno-palestino sobre el gobierno de Pinochet sigue siendo positiva (Schwabe, 2018).

En el ámbito político, por un lado, algunos palestinos jugaron un papel importante en la preparación del golpe de estado, como los hermanos Juan y Alberto Kassis Sabag, empresarios del sector alimentario que después ampliarían negocios a los sectores bancario y mediático. De hecho, Alberto Kassis es uno de los fundadores de la Fundación Pinochet. Por otro lado, otros chileno-palestinos fueron condenados al exilio por sus inclinaciones políticas a favor del gobierno del presidente Allende, como el cineasta Miguel Littín, el poeta y embajador Mahfud Massís ${ }^{2}$ y el político y exministro Rafael Tarud (el "Turco Tarud") 3 (Baeza, 2013). Otros, como el poeta y profesor universitario Andrés Sabella, de izquierdas y cercano a Pablo Neruda, permaneció en el país, pero fue destituido de su cargo académico durante la dictadura (Sabella, 2017).

Paradójicamente, la industria textil creada por los palestinos, hasta entonces tan importante para la economía chilena, sufrió las consecuencias del modelo neoliberal implantado abruptamente por el régimen de Pinochet, encabezado por otro descendiente de palestinos, su ministro de Economía, Jorge Cauas Lama. En 1975, la producción había caído un 31 \% y varias empresas terminaron en bancarrota, debido a la agresiva apertura del mercado chileno a las importaciones (Baeza, 2013), sobre todo, provenientes del mercado chino (Molina, 2014).

No obstante, la mayoría de estos empresarios logró recuperarse y, al igual que otros muchos, se vieron obligados a expandirse a otras áreas de negocios como el bancario, el inmobiliario, vitivinícola, de grandes superficies, medios de comunicación, etc. (Molina, 2014). Hoy en día, grandes empresas como Parque Arauco y el Banco de Crédito e Inversiones siguen estando en manos de familias de origen palestino, como se ha mencionado anteriormente.

Conforme los descendientes de la primera y segunda generación de inmigrantes fueron escalando social y económicamente, se fueron mudando a mejores barrios. Actualmente, aproximadamente siete de cada diez descendientes de inmigrantes árabes en la capital chilena viven en barrios de clase media, media alta

2 Mahfud Massís (Antonio Massís), premiado poeta y ensayista, comprometido con la lucha contra el colonialismo y la causa palestina. Fue presidente de la Sociedad de Escritores de Chile, del Instituto Árabe de Chile y, con el gobierno de Allende, agregado cultural de Chile en Venezuela hasta el golpe de Estado de 1973, cuando fue removido de su cargo y exiliado del régimen

3 Empresario y político de izquierdas, fue Ministro de Economía y Comercio, y de Minas durante el gobierno de Carlos Ibáñez del Campo en la década de 1950, y senador entre 1957 y 1973, hasta el golpe militar. 
y alta (Agar, 2006) como Las Condes y Providencia (Zahded, 2012). Aunque la pluralidad y división política se mantiene respecto al devenir político chileno, sí suele haber una postura relativamente homogénea al abordar la cuestión palestina (Schwabe, 2019), sobre todo a partir de 1982, como se verá adelante.

\section{La identidad de los chilenos de origen palestino}

Sobre las pautas del comportamiento sociopolítico de la comunidad palestina, no sólo en el caso chileno sino en la diáspora palestina en general, Abu Tarbush (2005) distinguirá dos niveles de identidad nacional diferenciados, relacionados con los diferentes momentos históricos del flujo migratorio de este pueblo. Por un lado, las primeras emigraciones impulsadas por factores económicos tendrán unas señas de identidad más débiles, porque correrán paralelamente a la formación de la identidad palestina, antes del conflicto de 1948, y porque se centraron más en la búsqueda de bienes materiales (individuales y familiares) que en los políticos (intrínsicamente de carácter público y colectivo). Por otro lado, las corrientes migratorias generadas después de la Nakba, de carácter estudiantil y profesional, fueron forzadas por el conflicto palestino-israelí y formaban parte del proceso de reemergencia nacional, por lo que sus señas de identidad nacional serían mucho más fuertes.

El proceso de integración de esta comunidad a la sociedad chilena estuvo pautado también por las propias características de la sociedad de acogida. Ya se ha mencionado que los primeros migrantes viajaban con documentos del Imperio Otomano, un mundo exótico y ajeno para las sociedades latinoamericanas de finales del siglo XIX y principios del XX, que preferían y primarían la inmigración europea. Los palestinos y árabes en general sufrieron en ocasiones rechazo y desprecio, en una especie de "turcofobia" que se fue disipando a lo largo del siglo XX. Muchos inmigrantes castellanizaron su nombre o apellidos, por ejemplo, los Al-Farid en Alfredo o los Yamil en Emilio (Zahded, 2012), mientras la familia Min dar Al Hadwah pasó a ser la familia Jadue (Palma, 2017), o pusieron nombres españoles a sus hijos, y se esforzaron por hablar un buen castellano para evitar las burlas y remedos de los nacionales, así perdieron, en pocas generaciones, la lengua materna. Incluso algunos dejaron de hablar el árabe en presencia de sus hijos para forzar su integración en la sociedad chilena (Zahded, 2012, p. 24)

Tal como indica Agar (2001), la sociedad chilena ejerció "una presión discriminatoria contra aquellos grupos cuyo origen escapaba a los patrones cristianooccidentales", lo que dificultó el proceso inicial de adaptación de los primeros llegados. No obstante, el mismo autor reconoce, en otro trabajo, que pese a los 
prejuicios y discriminación inicial, nunca hubo persecuciones o campañas para expulsarlos del país, y que los matrimonios mixtos que surgieron desde las primeras oleadas, aunque pocos, fueron muestra de que hubo formas de aceptación (Agar y Saffie, 2005).

Paradójicamente, la paulatina integración de los palestinos en Chile trajo consigo la necesidad de preservar sus rasgos identitarios y construir o reconstruir su memoria comunitaria. Las diferentes organizaciones creadas por los palestinos fueron voluntaria o involuntariamente, creadores y transmisores de esos rasgos comunitarios y de creación de memoria. Cabe destacar el papel de los medios de comunicación árabes que se crearon en Chile como Al-Watan o Mundo Árabe para afianzar este proceso, que crearon plataformas de interconexión entre los migrantes árabes y entre ellos y Palestina, las cuales fortalecieron la sobrevivencia de la comunidad árabe en Chile.

Baeza (2013) indica que hasta 1920, los inmigrantes de Palestina se identificaban a sí mismos basados en su ciudad o pueblo de origen, principalmente Belén, Beit Yala o Beit Sahur; basados en Bilad al-Sham, es decir, la provincia otomana que comprendía Siria, Líbano y Palestina; en su religión, mayoritariamente cristiano-ortodoxa, y en su conciencia de provenir de Tierra Santa y, finalmente, su arabidad. Las referencias a Palestina, aunque existían, eran mínimas. No obstante, los cambios introducidos a partir de 1923 en Oriente Medio que complicarían las circunstancias políticas y sociales en la Palestina histórica perfilarían una nueva identidad de carácter nacional entre los palestinos residentes en Chile.

Así pues, hasta el desmembramiento del Imperio Otomano, muchos emigrados iban y volvían a sus ciudades de origen regularmente por negocios o por asuntos familiares, viajaban con sus pasaportes otomanos hasta que expiraron con el tratado de Lausana y la implantación del régimen de Mandato en Palestina en 1923. Entonces, aquellos palestinos residentes en el extranjero debían solicitar en los consulados británicos un "Certificado de emergencia" que les permitiera volver a su país, pero el documento especificaba que no garantizaba el ingreso o permanencia en Palestina. Posteriormente, en 1925 el gobierno británico lanzó un decreto de nacionalidad palestina ${ }^{4}$, que dificultaba la obtención de pasaportes palestinos para aquellos árabes residentes fuera del país y facilitaba la obtención a las crecientes oleadas de judíos que ingresaban al Mandato, mayoritariamente desde Europa (Bawasla, 2018).

4 Dicha nacionalidad palestina terminó con el final del Mandato Británico y posterior creación del Estado de Israel. 
Como resultado de ello, hacia finales de la década de 1930, entre los residentes en Chile existe ya una creciente conciencia de pertenecer a una "nación palestina”, a la vez que seguían el proceso de inserción en el país de acogida, paradójicamente, a costa de la pérdida de algunas características nacionales como la lengua árabe (Baeza, 2013). Así pues, el devenir histórico de la Palestina histórica iría marcando las diferencias entre los inmigrantes árabes provenientes de Siria, El Líbano y Palestina, que originalmente compartían tradiciones, religión y cultura (Zahded, 2012)

Los medios de comunicación árabes en Chile constituyen evidencias claras de la evolución de la conciencia comunitaria y nacional de los palestinos residentes en el país. Entre 1912 y 1930, circularon en Chile una decena de periódicos en árabe, entre ellos Al-Watan ${ }^{5}$ y $A s h$-Sharq, que comenzaron a distinguir entre sus lectores a los sirios, libaneses y palestinos y éstos a autodefinirse no sólo como árabes. También reflejaban las inquietudes de la comunidad palestina en el país ante el decreto británico de nacionalidad palestina de 1925 (Bawasla, 2018). Hebba El Attar (2019) realiza una amplia revisión histórica de los diferentes medios que han existido en el país, iniciando por Al-Islah (La Reforma), revista periódica publicada de 1930 a 1942 y que se distribuyó también en Perú, Bolivia y Ecuador, que fomentaba la cultura e identidad palestinas y reivindicaría la causa nacional. A partir de 1947, se recuperaría dicha publicación con el nombre de Mundo Árabe, con muchos menos textos en ese idioma ${ }^{6}$.

Otro ejemplo, siguiendo a El Attar, es el primer programa de radio de la comunidad palestino-chilena, La voz de Palestina, presentado por Fuad Habash ${ }^{7}$ y emitido desde los sesenta hasta finales de los setenta, que se emitiría en árabe hasta 1973, y luego obligado a transmitir sólo en español tras el golpe de Estado. Su heredero sería el programa Punto de contacto producido y presentado por Eugenio Chahuán, catedrático del Departamento de Estudios Árabes e Islámicos de la Universidad de Chile y emitido entre 1981 y 2002. A finales del siglo XX, Kiko Siade lanzaría Raíces árabes, otro programa radial y luego digital, que enfatizaba la cultura palestina, sobre todo la música árabe. Actualmente, la Federación Palestina en Chile emite Palestina por Siempre, un programa semanal de la radio de la Universidad de Chile que abarca la historia, la cultura y noticias de la Madre Patria y los recuerdos y memorias construidas o

5 Al Watan, lanzado en 1920 fue el periódico árabe que perduró más, circuló por 9 años y que, al publicar también en español pudo acceder a un público más amplio.

6 En su página electrónica se pueden encontrar los números desde 1930 hasta 2014. http://www.mundoarabe.cl/

7 Fuad Habash fue un inmigrante palestino de ideología comunista, profesor de árabe en Jerusalén, que estuvo encarcelado en Jordania antes de aterrizar en Santiago. Junto al poeta de origen palestino Mahfud Massís fundó el Frente para la Liberación de Palestina, que tenía en Chile su propia publicación, Palestina Patria Martir. 
reconstruidas por los inmigrantes palestinos en Chile. Asimismo, la Fundación Palestina Belén 2000 (de la que se hablará posteriormente) publica, desde 2001 de forma bimensual la revista Al-Damir, que comenzó como una publicación enfocada a la comunidad palestina en su conjunto, pero que ha ido transitando hacia una publicación enfocada sólo a la clase empresarial de dicha comunidad, omitiendo información controversial sobre Palestina (Smith, 2012).

Sin desmeritar el papel ejercido por esos medios, se debe señalar que el compromiso de esa comunidad palestina respecto a la patria de origen no fue homogéneo. Las diferencias sociales, económicas y políticas de la década de los setenta se reflejaban en distintos posicionamientos respecto al conflicto en Palestina, especialmente en las décadas de 1960 y 1970. Si en algunos sectores el activismo político a favor de la Organización para la Liberación de Palestina (OLP) y otras organizaciones palestinas era visible y abierto, al estar relacionados con otros movimientos de liberación nacional, revolucionarios o de izquierdas de América Latina, eran vistos con sospecha, y como una oposición al régimen militar chileno, por parte del gobierno de Pinochet (Schwabe, 2018) y de ciertos sectores empresariales palestinos de derecha, como el textil.

No obstante, la masacre de refugiados en los campamentos de Sabra y Chatila en el Líbano en 1982, constituyó, según Baeza (2013), un punto de inflexión en la postura de la comunidad palestina en Chile, que se unificó para rechazar dicho hecho. Desde entonces y hasta ahora, pese a que los chileno-palestinos se encuentran divididos en todo el espectro político del país, sus posturas respecto a Palestina son de franca y abierta cooperación. Ejemplo claro de ello es el Grupo Interparlamentario Chileno - Palestino que promueve las relaciones entre ambos pueblos y defiende las posturas palestinas en el congreso del país, y que en ocasiones se enfrenta a la bancada pro-israelí de este mismo. Evidencia del peso político de esta comunidad es la inauguración en 2010 de una placa en la plaza Chile de Beit Yala, localidad bajo la Autoridad Nacional Palestina que, financiada por el gobierno chileno, conmemora 200 años de independencia del país sudamericano, y honra a sus propios ciudadanos de origen palestino. Otros ejemplos son la inauguración de la rotonda Chile en Belén, o la participación de delegados chilenos, entre ellos varios alcaldes de origen palestino en las convenciones de la Diáspora del Distrito de Belén (Ministerio de Relaciones Exteriores, 2019)

En el ámbito social, existen decenas de instituciones de alcance nacional, regional y local que los migrantes palestinos han ido construyendo a lo largo y ancho de la geografía chilena. A continuación, se indican los principales de carácter nacional. 
La organización de alcance más amplio es, sin duda, la Federación Palestina de Chile, que aglutina organizaciones sociales, políticas, religiosas, culturales y de beneficencia, y que, según su propia página web (Federación Palestina de Chile, s. f), representa a esta colectividad no sólo ante el resto de la sociedad chilena, sino ante la OLP, la Autoridad Nacional Palestina y otras organizaciones palestinas del mundo.

Otra iniciativa importante es la Fundación Belén 2000, creada en 2001 por empresarios chileno-palestinos y dedicada, en primer lugar, a auxiliar a menores palestinos de los territorios ocupados, también a realizar actividades culturales y de cabildeo. Además de su página electrónica, cuenta con una publicación mensual llamada Al-Damir, que difunde las actividades organizadas dentro de esta comunidad, cuenta historias de éxito de sus miembros y da seguimiento a la situación política y social de Palestina.

Una institución con presencia en el ámbito universitario es el capítulo chileno de la Unión General de Estudiantes Palestinos (UGEP) ${ }^{8}$, organización que es parte de la OLP. El brazo chileno se crea en la década de 1980 y, aunque desaparecería por un tiempo tras los Acuerdos de Oslo, sigue como un elemento activo entre la comunidad palestina. Otra institución quizá con mayor trascendencia es el Comité Democrático Palestino-Chile, creada en 1998 y autodescrita como una organización no gubernamental que trabaja en pro de la difusión de la cultura, historia, tradiciones y la causa palestina, y que publica la web palestinalibre.org

\section{Presente y futuro}

Los palestinos son ya un grupo asimilado, con pérdida de la lengua árabe, buena parte católica por los matrimonios mixtos-en 2001, un $38 \%$ con un padre o madre cuyo origen no es árabe (Agar,2006)-, pero que mantienen algunos rasgos de apego a su cultura de origen como la familia, entendida como "una amplia red afectiva y solidaria-la colmena árabe-, de carácter local y global" (Cánovas, 2011), la comida y algunas tradiciones. De hecho, para Nicholas Bascuñan-Wiley (2019), el mantenimiento de la gastronomía palestina es una forma de resistencia al olvido de la diáspora y de conexión con Palestina. Destaca entre todo el papel de la estructura familiar. En este sentido, el papel fundamental

8 La UGEP fue creada en 1959 por Yaser Arafat y Abu Jihad en El Cairo para "liberar" a la patria y tiene representación en un centenar de países. En Chile, se crea en los años ochenta y desaparece por un tiempo tras los Acuerdos de Oslo. 
de la familia compuesta ${ }^{9}$ en la cultura árabe y el sentimiento de lealtad hacia la comunidad de origen explican, según Agar (1997), el comportamiento espacial y socioeconómico de los inmigrantes árabes en el proceso de integración en Chile.

En una encuesta de 2001 a la población chilena de origen árabe acerca de su autodefinición identitaria, un $65 \%$ se consideró chileno-árabe, un $13 \%$ árabechileno y un $12 \%$ chileno a secas (Agar, 2006). Se observa, pues, un proceso integrador exitoso donde ya es el chileno el elemento identitario nacional más importante. No obstante, ello no implica necesariamente que el siguiente paso sea la pérdida de la palestinidad en esta filiación compleja.

La cuarta generación de chileno-palestinos, a la vez que está totalmente integrada en la sociedad chilena y mantiene un sentimiento profundo de pertenencia al país, mira también sus raíces palestinas para reencontrarlas o ahondar en ellas, orgullosos de sus apellidos árabes y conscientes de la situación en Palestina (Bascuñan-Wiley, 2017). Según Agar (2006), en las últimas décadas se observa un renacer de lo étnico que se manifiesta, por ejemplo, con el retorno de muchos jóvenes árabes a la Iglesia Ortodoxa de sus ancestros. Pero también se manifiesta en el creciente interés por las tradiciones y las culturas palestinas, especialmente la música y la comida, (Zahded, 2012) y el devenir político en Oriente Medio potenciado por las nuevas tecnologías, las redes sociales e incluso los viajes a la Madre Patria (Debarbieri, 2020; Farah, 2020; Pichara, 2019). Este interés está ligado al compromiso político con la causa palestina, que considera el propio reconocimiento de los orígenes palestinos de esta comunidad como una forma de resistencia política a lo que sucede en Oriente Medio y de apoyo al pueblo palestino (Schwabe, 2018, p. 652).

Todo ello permite, a las nuevas generaciones, reencontrarse con su pasado y reafirmar su pertenencia a la comunidad palestina en Chile. Un ejemplo de ello es la creación artística de Miguel Littín, cineasta palestino-chileno, a través de su documental Crónicas palestinas (2002) o su película La última luna (2005) que tratan sobre Palestina y sus emigrantes que llegaron a Chile (El Attar, 2018). Finalmente, en el ámbito deportivo también se observa una creciente politización entre seguidores y plantel del Club Palestino, mencionado anteriormente. Es común ver a sus seguidores mostrando carteles reivindicando la palestinidad de Jerusalén o en contra de la ocupación israelí y la guerra en Gaza. Aunque tradicionalmente, tal como señala Vidal (2016), Palestina no ha tenido un discurso político institucional tan marcado ni evidente, en los últimos años la directiva ha establecido lazos formales con la Autoridad Nacional

9 Es decir, familia extensa (familia nuclear más otros parientes no-nucleares) más otros no-parientes. 
Palestina (como la visita del presidente de la ANP, Mahmud Abás, a sus instalaciones y plantilla en mayo de 2018), y ha aumentado su compromiso con la causa palestina.

\section{Conclusiones}

La comunidad palestina en Chile constituye un caso exitoso de integración en todos los ámbitos. Los primeros inmigrantes lograron superar las dificultades económicas y sociales que les acarreaba su origen otomano y árabe, sin contar con los beneficios que el gobierno chileno ofrecía a otros colectivos de origen europeo, como parte de su política de inmigración selectiva. Dicha integración no ha supuesto, necesariamente, la completa asimilación de este colectivo a la sociedad chilena, dado que aún conserva ciertos rasgos culturales propios, en especial en el ámbito familiar, y cierta conciencia colectiva que perdura tras más de un siglo de la llegada de los primeros inmigrantes árabes al país andino. Con la excepción de los palestinos llegados en 2008, no existen evidencias de tensiones entre esta comunidad -heterogénea en términos sociales, económicos y políticos-, con el resto de la sociedad chilena, de la que es parte integral y activa. Es decir, sus miembros son ciudadanos de pleno derecho del Estado chileno.

Los acontecimientos en Oriente Medio después de la Primera Guerra Mundial influirían en la configuración identitaria de la comunidad palestina chilena. La propia construcción identitaria colectiva correría en paralelo y se vería influida por la evolución del nacionalismo palestino, marcado por el mandato británico en Palestina en 1923, la creación del Estado de Israel en 1948 y la posterior ocupación total de la Palestina histórica a partir de 1967.

El caso de este colectivo es relevante en cuanto que es la comunidad palestina fuera de Oriente Medio más numerosa, más organizada y con influencia suficiente para tener presencia propia en los diferentes ámbitos de la sociedad chilena, desde el deporte, el mundo empresarial, hasta la representación política. La participación de políticos de origen palestino en la política nacional ha influido la política exterior de Chile respecto a la cuestión palestina, que en las últimas décadas se manifiesta en un acercamiento a la OLP y a la Autoridad Nacional Palestina.

Aunque en el presente la inmensa mayoría se identifica primeramente como chilenos-árabes, lejos de diluirse, hasta cierto punto la identidad palestina se refuerza desde dentro. Tanto la organización y activismo social de la comunidad, como el interés de las generaciones más jóvenes por redescubrir de sus propias raíces - pese a la pérdida del idioma árabe y otros elementos identitarios-, y, 
sobre todo, el activismo político hacia Palestina, hacen prever la permanencia de los lazos que unen a los miembros de esta comunidad, así como su interés por el devenir histórico del país de sus ancestros.

\section{Referencias}

Abu-Tarbush, J. (2005). La recreación de la identidad palestina en la diáspora árabe y occidental. Revista Cuadernos de Estudios Árabes, 1(1), 98-92.

Agar, L. (2006). Árabes y judíos en Chile: Apuntes sobre la inmigración y la integración social. En Klich, I. (Comp.), Árabes y judios en América Latina. Historia, representaciones y desafios (pp. 151-177). Siglo XXI Editora Iberoamericana.

Agar, L. y Saffie, N. (2005). Chilenos de origen árabe: La fuerza de las raíces. Revista Miscelánea de Estudios Árabes y Hebraicos Sección Árabe-Islam, 54, 3-27.

Agar, L. y Rebolledo, A. (1997). La inmigración árabe en Chile: Los caminos de la integración. En Kabchi, R. (Coord.), El mundo árabe y América Latina (pp.283-309). UNESCO.

Arad, R. (2018). Meet the Chilestinians, the Largest Palestinian Community Outside the Middle East. Haaretz. https://www.haaretz.com/middle-east-news/ palestinians/.premium.MAGAZINE-the-largest-palestinian-communityoutside-the-mideast-thrives-in-chile-1.6613371

Araneda, J. (2015). Las ilusiones y los padecimientos de la emigración: El caso de los inmigrantes árabes musulmanes levantinos a Chile 1930-1950. Tabula Rasa (22), 125-146.

Baeza, C. (2013). Palestinians in Latin America: Between Assimilation and Longdistance Nationalism" https://www.thejerusalemfund.org/4198/palestiniansin-latin-america-between-assimilation-and-long-distance-nationalism

Bascuñan-Wiley N. (2017). Contextualizing Palestinian Hybridity: How Pragmatic Citizenship Influences Diasporic Identities. Sociology Honors Projects, 50. http://digitalcommons.macalester.edu/soci_honors/50

Bascuñan-Wiley N. (2019). Sumud and food: Remembering Palestine through cuisine in Chile. Mashriq \& Mahjar 6(2), 100-131. https://oi. org/10.24847/66i2019.239

Bawalsa, N. (2018). Palestine West of the Andes. NACLA-Report on the Americas, 50 (1), 34-39. doi: 10.1080/10714839.2018.1448592 
Cánovas, R. (2011). Letras judías y árabes en Chile: Otros cobijos. América sin nombre, 16, 131-140. http://dx.doi.org/10.14198/AMESN2011.16.13

Carrasco, C., Molina, M. y Baltar, M. (2013). Inmigración, infancia e integración socioeducativa: Un estudio etnográfico sobre niños palestinos en Chile. Revista chilena de Antropología, 27, 141-169.

Contreras, P. (2015). Memorias e identidades colectivas en refugiados palestinos reasentados en Chile. Crítica y Emancipación, 7(14), 15-43.

Debarbieri, S. (2020) "Hoy más que nunca necesitamos el apoyo de todos. AlDamir, 134, 22-23

El Attar, H. (2019). Memorias acústicas palestino-chilenas: El caso de Palestina por siempre. MEAH, sección árabe-islam, 68, 441-450. https://doi.org/10.30827/ meaharabe.v68i0.1009

Farah, C. (2020). Cuando la causa es el trabajo de cada día. Al-Damir, 134, 40-41.

Federación Palestina de Chile. (s. f.). Nuestra historia. Recuperado el 26 de mayo de 2020, http://www.federacionpalestina.cl/nuestra-historia/

Holston, M. (2005). Proud Palestinians of Chile. Americas; 57(6), 5-6.

Leal, A., Palomera, A. y Norambuena, C. (2019). Protection and Refugee in Brazil and Chile: the Case of Palestinian Refugees: an Analysis from the Model of Economic and Cultural Adaptation. Journal of International Migration and Integration. https://doi.org/10.1007/s12134-019-00696-7

Lekanda, P. (2008). Chile y la obligación ética de recibir refugiados: Los refugiados palestinos vistos como un caso imperativo. Revista Pléyade, 2, 140-155.

Ministerio de Relaciones Exteriores de Chile. (2019). Convención de la diáspora palestina en Belén, Beit Jala y Beit Sahour. Representación de Chile ante el Estado de Palestina. https://chile.gob.cl/palestina/en/site/tax/port/all/taxport_6___1.html

Molina, P. (2014). Por qué Chile es el país con más palestinos fuera del mundo árabe e Israel $B B C$ News. Recuperado de https://www.bbc.com/mundo/noticias/2014/08/140813_chile_palestinos_comunidad_jp .

Moore, A. y Mathewson, K. (2013). Latin America's Los Turcos: Geographic Aspects of Levantine and Maghreb Diasporas. Nóesis Revista de Ciencias Sociales y Humanidades, 22(43-2), 290-308. http://dx.doi.org/10.20983/noesis.2013.2.7

Palma, J. (2017). Programa "Yo soy palestino”: Resistencia y resignificación cultural de la comunidad palestina en Chile [Tesis de grado. Universidad de Chile, Santiago]. 
Pichara, K. (2019). Taqalid Una sola familia. Al-Damir, 133, 13-14.

Sabella, B. (2017). Jerusalem and Bethlehem Immigrant Families to Chile in the Early Twentieth Century. Jerusalem Quarterly, 72, 58-66.

Schwabe, S. (2018). Paradoxes of erasure: Palestinian Memory and the Politics of Forgetting in Post-Dictatorship Chile. Interventions 20(5), 651-665. https:// doi.org/10.1080/1369801X.2018.1487793

Smith, D. (2012). Discursos hegemónicos y corrientes alternativas en la colectividad palestina de Chile [Tesis de maestría. Concordia University, Montreal].

Smith, D. (2010). From Haifa, to Baghdad and then Santiago: Chile's Palestinian refugee community, past and present. Al-Majdal Quartrly Magazine, 45, 3034.

Sumamé, M. (2003). Transculturación, identidad y alteridad en novelas de la inmigración árabe hacia Chile. Signos: estudios de lengua y literatura, 36(53), $51-73$.

Vera, M. (2017). Reasentamiento de refugiados extrarregionales en Sudamérica: La experiencia palestina. Forced Migration Review, 56, 47-49.

Vidal, N. (2016). Club Deportivo Palestino, la singular historia del campeón de la Copa Chile. De Cabeza 1, 27-35.

Zahded, A. (2012). La comunidad palestina en Santiago de Chile. Un estudio de la cultura, la identidad y la religión de los palestinos chilenos [tesis de maestría. Universidad de Bergen, Noruega]. 